\title{
Progress in plant protoplast research
}

\author{
Tom Eeckhaut • Prabhu Shankar Lakshmanan • \\ Dieter Deryckere $\cdot$ Erik Van Bockstaele • \\ Johan Van Huylenbroeck
}

Received: 14 May 2013 / Accepted: 18 July 2013 / Published online: 17 August 2013

(C) Springer-Verlag Berlin Heidelberg 2013

\begin{abstract}
In this review we focus on recent progress in protoplast regeneration, symmetric and asymmetric hybridization and novel technology developments. Regeneration of new species and improved culture techniques opened new horizons for practical breeding in a number of crops. The importance of protoplast sources and embedding systems is discussed. The study of reactive oxygen species effects and DNA (de)condensation, along with thorough phytohormone monitoring, are in our opinion the most promising research topics in the further strive for rationalization of protoplast regeneration. Following, fusion and fragmentation progress is summarized. Genomic, transcriptomic and proteomic studies have led to better insights in fundamental processes such as cell wall formation, cell development and chromosome rearrangements in fusion products, whether or not obtained after irradiation. Advanced molecular screening methods of both genome and cytoplasmome facilitate efficient screening of both symmetric and asymmetric fusion products. We expect that emerging technologies as GISH, high resolution melting and next generation sequencing will pay major contributions to our insights of genome creation and stabilization, mainly after asymmetric hybridization. Finally, we demonstrate agricultural valorization of somatic hybridization
\end{abstract}

T. Eeckhaut $(\bowtie) \cdot$ P. S. Lakshmanan · D. Deryckere

E. Van Bockstaele · J. Van Huylenbroeck

Institute for Agricultural and Fisheries Research (ILVO),

Plant Sciences Unit, Applied Genetics and Breeding,

Caritasstraat 21, 9090 Melle, Belgium

e-mail: tom.eeckhaut@ilvo.vlaanderen.be

P. S. Lakshmanan · E. Van Bockstaele

Department of Plant Production, Faculty of Bioscience

Engineering, Ghent University, Coupure links 653,

9000 Ghent, Belgium through enumerating recent introgression of diverse traits in a number of commercial crops.

Keywords Genome fragmentation · Hybrid screening · Interspecific hybridization - Protoplast regeneration .

Somatic fusion
Abbreviations
CMS Cytoplasmic male sterility
MPP Microprotoplast
ROS Reactive oxygen species

\section{Introduction}

Plant cells from which the cell wall has been enzymatically or mechanically removed are called protoplasts. Theoretically, protoplasts are totipotent, meaning that they have the capability to dedifferentiate, re-enter the cell cycle, go through repeated mitotic divisions and then proliferate or regenerate into various organs. Fusion of protoplasts from different species, therefore, supplies a practical breeding tool (Johnson and Veilleux 2001) and circumvents sexual hybridization related prezygotic or postzygotic barriers. It can create different homokaryon or heterokaryon types, as well as alloplasmic hybrids (cybrids) (Xia 2009).

Regeneration is often the bottleneck in somatic hybridization breeding programs, which has forced researchers to come up with more innovative approaches, such as electrical stimulation, non-ionic surfactants and artificial gas carriers (Davey et al. 2005). Nonetheless, protoplast fusion became a common technique for the introduction of novelties in commercial crops. During the last decade, interest in protoplast research was renewed, partly due to public antagonism toward genetically modified organisms. 
Recently, Davey et al. (2010) and Grosser et al. (2010) published practical manuals with numerous protocols for isolation, culture, fragmentation and fusion.

In this review we highlight the technological breakthroughs that were made during the last decade in spermatophytes protoplast related research. This survey does not aim to cite all protoplast related research, but to provide an overview of the most innovative developments and insights. We critically discuss recent achievements and speculate on new multidisciplinary approaches that can enhance further implementation.

\section{Rationalization of regeneration}

Table 1 summarizes the main plant species for which progress in protoplast culture has been documented over the last 10 years. The most suitable culture method, including optimal protoplast density, and the most efficient protoplast source have been listed. Donor material type has often been decisive for successful regeneration, demonstrating protoplast variability within a single genotype depending on the exact protoplast source. For instance, suspension cells contain more mitochondria than mesophyll cells, and for monocotyledonous species often represent the most suitable donor material (Chabane et al. 2007). Within a single genotype, protoplast variability can arise due to somaclonal variation, but also to different antioxidant and phytochemical concentrations that may be source inherent and can affect regeneration capacity (Pan et al. 2005). In our opinion, explant variability, whether genetically or physiologically, should be further exploited to enable protoplast regeneration in recalcitrant crops. Indeed, relatively few efforts have been done to increase variability within the explants. Pretreatments usually are narrowed down to phytohormonal treatment, whereas ploidy manipulation, antioxidant treatments and metabolism enhancers could possibly prove more efficient in a number of species.

Recent results have led to a better understanding of the importance of culture systems. The relatively low colony formation in liquid medium is assumed to be caused by a shortage of aeration and light (Azad et al. 2006) or a release of toxic components (Duquenne et al. 2007). Semi-permeable membranes (Niedz 2006) for improving oxygen supply or microfluidic polydimethylsiloxane channels with microtubes for continuous medium supply (Ko et al. 2006) can significantly enhance regeneration efficiency. A general finding was the better regeneration of alginate or agarose-embedded protoplasts. In Cichorium, a universal regeneration system could be accomplished by agarose bead culture (Deryckere et al. 2012). For other crops, as well beads, discs, layers, thin layers or extra thin films are used (Pati et al. 2005; Rakosy-Tican et al. 2007; Prange et al. 2010a; Grzebelus et al. 2012a; Kielkowska and Adamus 2012). A major advantage of embedding systems is the easy refreshment of the cultures. This minimizes possible negative effects toward microcolony development and microbial contamination. When discs are used, protoplasts divide at a higher rate at the edge (Rakosy-Tican et al. 2007). The thinner the matrix, the higher were the plating efficiencies (Pati et al. 2005). Rotation of the alginate/protoplast suspension during application and before polymerization minimizes layer thickness (Grzebelus et al. 2012a). Also the embedding agent type affects the final outcome, possibly by interacting with genotype, osmolarity, temperature, culture system or aeration (Prange et al. 2010a; Kielkowska and Adamus 2012). This is in accordance with earlier postulations on the positive effect of embedding by membrane stabilization through lipid peroxidase inhibition, the prevention of leakage of cell wall precursors or other metabolites, and lower ethylene levels (Bajaj 1989). Moreover, protoplast aggregation leading up to poor oxygen supply and browning is avoided (Pati et al. 2008; Lian et al. 2011). Also, the osmotic pressure changes steadily instead of stepwise (Kanwar et al. 2009). Another advantage of protoplast embedding may be an improved signaling cascade before the first cytokinesis. Before dedifferentiated plant cells enter cell division, the vacuole develops a complex architecture. This enhances division through better nuclear positioning (Sheahan et al. 2007). In the model proposed by Zaban et al. (2013), the cytoskeleton interacts with this nuclear positioning and thus controls activation and release of molecules involved in cell wall synthesis. Subsequently, dynamic actin filaments are indispensable for the induction of a new cell pole, required for elongation. Briere et al. (2004) suggested that in agarose-embedded protoplasts the actin microfilament network is involved in this signaling process, leading to polarity acquisition and embryoid determination. The aforementioned techniques designed for culturing protoplasts in very narrow matrices hold potential for many previously recalcitrant crops. In addition to further technical improvements, a better biochemical characterization of oxygen deficiency in protoplast culture could provide useful data for further breakthroughs.

Original media supplementations have recently contributed to regeneration of some afore recalcitrant species or materials. In Beta vulgaris, the plating efficiency of mesophyll cells drastically increases after adding $100 \mathrm{nM}$ phytosulfokine, a peptide growth factor, which has antioxidant properties but possibly also generates a nurse cell effect (Grzebelus et al. 2012b). The supply of exogenous arabinogalactan protein-rich extracts significantly improved organogenesis from protoplast derived callus (Wisniewska and Majewska-Sawka 2007). Galactoglucomannan-derived oligosaccharides are signaling molecules in plant cell elongation and differentiation. They positively influenced protoplast viability and regeneration (Kakoniova et al. 2010). 
Table 1 Progress on protoplast regeneration in different plant species in the period 2004-2013

\begin{tabular}{|c|c|c|c|c|c|}
\hline Plant species & $\begin{array}{l}\text { Protoplast } \\
\text { source }^{\mathrm{a}}\end{array}$ & Culture method & $\begin{array}{l}\text { Protoplast density } \\
\left(\times 10^{4} / \mathrm{ml}\right)\end{array}$ & Result $^{\mathrm{b}}$ & References \\
\hline Alstroemeria spp. & $\mathrm{C}$ & Liquid & 10 & $\mathrm{P}$ & Kim et al. (2005) \\
\hline Anthurium scherzerianum & SE & Agarose beads & 10 & $\mathrm{MCO}$ & Duquenne et al. (2007) \\
\hline Beta vulgaris & M & Thin alginate layer & 40 & $\mathrm{MC}$ & Grzebelus et al. (2012b) \\
\hline Brassica oleracea & $\mathrm{H}$ & Agarose embedded, coculture & 10 & $\mathrm{P}$ & Chen et al. (2004) \\
\hline Brassica oleracea & $\mathrm{H}$ & Agarose embedded, coculture & 10 & $\mathrm{P}$ & Sheng et al. (2011) \\
\hline Brassica oleracea & $\mathrm{H}$ & Alginate layer & 40 & $\mathrm{P}$ & $\begin{array}{l}\text { Kielkowska and Adamus } \\
\text { (2012) }\end{array}$ \\
\hline Calibrachoa spp. & M & Liquid or alginate embedded & 15 & $\mathrm{~S}$ & Meyer et al. (2009) \\
\hline Chrysanthemum indicum & M & Liquid & 10 & $\mathrm{C}$ & $\begin{array}{l}\text { Eeckhaut and Van Huylen- } \\
\text { broeck (2011) }\end{array}$ \\
\hline Cichorium intybus & M & Agarose embedded & 5 & $\mathrm{P}$ & Deryckere et al. (2012) \\
\hline Citrus sinensis & $\mathrm{C}$ & Alginate beads & 25 & $\mathrm{E}$ & Niedz (2006) \\
\hline Cyclamen coum & $\mathrm{SC}$ & Agarose or alginate embedded & 15 & $\mathrm{P}$ & Prange et al. (2010b) \\
\hline Cyclamen persicum & $\mathrm{SC}$ & Alginate films & 15 & $\mathrm{P}$ & Winkelmann et al. (2006) \\
\hline Cyclamen spp. & SC & Agarose or alginate embedded & 15 & $\mathrm{P}$ & Prange et al. (2010a) \\
\hline Daucus carota & $\mathrm{H}$ & Thin alginate layer & 40 & $\mathrm{P}$ & Grzebelus et al. (2012a) \\
\hline Dianthus acicularis & $\mathrm{M}, \mathrm{SC}$ & Solid (Gelrite) & 10 & $\mathrm{P}$ & Shiba and Mii (2005) \\
\hline Echinacea purpurea & M & Alginate block/liquid & 10 & $\mathrm{P}$ & Pan et al. (2004) \\
\hline Gentiana kurroo & $\mathrm{SC}(\mathrm{CO})$ & Agarose bead cultures & 20 & $\mathrm{P}$ & $\begin{array}{l}\text { Fiuk and Rybczynski } \\
\text { (2007) }\end{array}$ \\
\hline Gossypium davidsonii & $\mathrm{SC}$ & Liquid over solid & $20-100$ & $\mathrm{P}$ & Yang et al. (2007) \\
\hline Gossypium hirsutum & SE, SC & Liquid & $20-100$ & $\mathrm{P}$ & Sun et al. (2005b) \\
\hline Gossypium hirsutum & SC & Liquid & 20 & $\mathrm{P}$ & Wang et al. (2008a) \\
\hline Gossypium klotzschianum & SE, SC & Liquid & $20-100$ & $\mathrm{P}$ & Sun et al. (2005a) \\
\hline Helianthus annuus & $\mathrm{H}$ & Alginate discs & 80 & $\mathrm{P}$ & Rakosy-Tican et al. (2007) \\
\hline Hypericum perforatum & $\mathrm{HC}$ & Alginate blocks & 20 & $\mathrm{P}$ & Pan et al. (2005) \\
\hline Ipomoea cairica & M & Liquid & $1-2$ & $\mathrm{P}$ & Guo et al. (2006) \\
\hline Iris fulva & $\mathrm{SC}$ & Agarose block & 10 & $\mathrm{P}$ & Inoue et al. (2004) \\
\hline Kalanchoë blossfeldiana & M & Liquid & 10 & $\mathrm{P}$ & Castelblanque et al. (2010) \\
\hline Lilium japonicum & $\mathrm{SC}$ & $\begin{array}{l}\text { Agarose embedded, nurse } \\
\text { cells }\end{array}$ & 10 & $\mathrm{P}$ & Komai et al. (2006) \\
\hline Lotus corniculatus & $\mathrm{CO}$ & Extra thin alginate film & 20 & $\mathrm{P}$ & Pati et al. (2005) \\
\hline Morus indica & M & Liquid & 10 & $\mathrm{P}$ & Umate et al. (2005) \\
\hline Musa acuminata & $\mathrm{SC}$ & Liquid, feeder layer & 100 & $\mathrm{P}$ & Xiao et al. (2007) \\
\hline Musa paradisiacal & $\mathrm{SC}$ & Liquid, feeder layer & 100 & $\mathrm{P}$ & Dai et al. (2010) \\
\hline Nicotiana tabacum & M & Extra thin alginate film & 10 & $\mathrm{P}$ & Pati et al. (2005) \\
\hline Petunia spp. & M & Liquid & 15 & $\mathrm{~S}$ & Meyer et al. (2009) \\
\hline Phalaenopsis sp. & $\mathrm{SC}$ & Solid, gellan gum & 10 & $\mathrm{P}$ & Shrestha et al. (2007) \\
\hline Phellodendron amurense & M & Solid, gellan gum & 40 & $\mathrm{P}$ & Azad et al. (2006) \\
\hline Phoenix dactylifera & $\mathrm{C}$ & Liquid, feeder layer & 100 & $\mathrm{C}$ & Chabane et al. (2007) \\
\hline Robinia pseudoacacia & $\mathrm{C}$ & Liquid & $20-40$ & $\mathrm{P}$ & Kanwar et al. (2009) \\
\hline Spathiphyllum wallisii & SE & Agarose beads & 10 & $\mathrm{MCO}$ & Duquenne et al. (2007) \\
\hline Ulmus minor & M & Agarose droplets & 20 & $\mathrm{MC}$ & Conde and Santos (2006) \\
\hline Zea mays & $\mathrm{SC}$ & Solid/feeder/liquid & $20-40$ & $\mathrm{P}$ & He et al. (2006) \\
\hline Zingiber officinale & $\mathrm{SC}$ & Liquid & $10-50$ & $\mathrm{P}$ & Guo et al. (2007b) \\
\hline
\end{tabular}

${ }^{a} C$ callus, $C O$ cotyledon, $H$ in vitro hypocotyls, $H C$ hypocotyls derived callus, $M$ mesophyll cells from in vitro leaves, $S C$ suspension cells, $S E$ somatic embryos

${ }^{\mathrm{b}} C$ callus, $E$ embryos, $M C$ microcalli, $M C O$ microcolonies, $P$ plants, $S$ shoots 
Polyamines are involved in a variety of growth and developmental processes in higher plants, and in stress responses. Isolation increases putrescine levels, especially in non-totipotent protoplasts (Papadakis et al. 2005). The intracellular polyamine levels and metabolism are possibly related to totipotency expression of plant protoplasts. Rakosy-Tican et al. (2007) propose spermidine to stimulate mitosis and to reduce stress impacts. Profiling multiple internal hormone levels during different regeneration phases with chromatographic tools (LC-HRMS and LCMS/MS) will allow to compare recalcitrant and regenerative genotypes, to administer exogenous hormones at the proper time and to monitor their metabolism closely. Furthermore, nowadays significant efforts are made to establish high throughput bioassays to discover novel molecules with potent cytokinin activities, as exemplified by Motte et al. (2013) for phenyl adenine. These could contribute to organogenesis in crops where traditional cytokinins have not induced shoot formation.

Oxidative stress evoked during protoplast isolation and culture may contribute to protoplast recalcitrance (Cassells and Curry 2001). Inclusion of ascorbate in the protoplast isolation medium of Arabidopsis leaves prevented protoplast damage (Riazunnisa et al. 2007). On the other hand, oxidative stress and auxins may act complementary to enhance growth cycle activity or differentiation (Pasternak et al. 2005). In Nicotiana tabacum protoplasts, glutathione induced cell dedifferentiation, similar to high auxin concentrations, whereas dehydroascorbate counteracted auxin mediated leaf protoplast development by its internal reduction to ascorbate; consequently, cell division was inhibited and cell expansion stimulated (Potters et al. 2010). Changes in the production of reactive oxygen species (ROS) and reactive nitrogen species were studied in more detail in cucumber protoplasts (Petrivalsky et al. 2012). The crucial role of controlled reactive oxygen and nitrogen species production in both regeneration and cellular growth and regeneration was confirmed. The different levels of as well ROS and antioxidant enzymes and scavengers in Citrus callus and mesophyll are suggested to play a key role in defining the regeneration potential of protoplasts of both cell types (Xu et al. 2013). Regeneration research would greatly benefit from more detailed studies on the effects of isolation and early culture on model plants antioxidant mechanisms. Further research could, therefore, be directed toward in vivo localization of diverse ROS and enzymes involved in either their production or detoxification. Specific consequences of ROS accumulations and enzyme activity could be monitored in both responsive and recalcitrant genotypes.

As mentioned before, protoplast isolation generates significant levels of stress and influences polyamine and ROS biosynthesis, both of which may negatively interfere with subsequent regeneration (Cassells and Curry 2001;
Papadakis et al. 2005). Xylanase and pectin lyase are components of commercial cellulase and pectinase that contribute to ROS formation (Ishii 1987); purified enzymes indeed generate less ROS (Papadakis and Roubelakis-Angelakis 1999). However, also non purified enzyme mixtures are efficient scavengers of extracellular peroxide (Yasuda et al. 2007); this indicates that mainly intracellular ROS are responsible for protoplast recalcitrance. To limit cell damage during isolation to the best possible extent, $\mathrm{Wu}$ et al. (2009) have developed the 'Tape Arabidopsis Sandwich' method that allows an easy removal of the lower epidermis and a more efficient exposure of mesophyll cells to the enzyme mixture. During protoplast isolation, endophytic bacteria can be released and subsequently cocultured (Klocke et al. 2012); their interaction with plant cells is probably quite complex, and we can speculate that their effect on protoplast regeneration can be either stimulative or inhibitory depending on the exact developmental phase, culture techniques and other circumstances.

Recent tools, e.g., suppression subtractive hybridization (Yang et al. 2008) have shown potential for genome studies, but also the proteome of developing protoplasts has received more attention (Kwon et al. 2005; De Jong et al. 2007). Holme et al. (2004) identified two quantitative trait loci that contribute to the regeneration ability of protoplast derived microcalli. This can be an initial step toward marker assisted selection of regeneration ability and/or gene introgression into recalcitrant species. In coming years, more fundamental knowledge on early divisions and microcolony formation will become available. To this end, transcriptome and proteome analyses should be implemented further.

Exploration of the link between osmolarity decrease and chromatin over condensation as hinted by Ondrěj et al. (2009) may also provide significant contributions toward understanding the complex interaction between genetic background and environmental conditions in early regeneration. Indications for the importance of antioxidants have yet been published in this matter (Ondrěj et al. 2010). On the other hand, a connection between ROS and cytosine hydroxymethylation that decreases chromatin recondensation after protoplast isolation, has not been demonstrated (Moricová et al. 2013).

Figure 1 shows a general model of the different steps of protoplast regeneration, compiling the most promising research areas for further research in the near future.

\section{Advances in protoplast fusion and fragmentation}

In recent years, chemical fusion and electrofusion were equally used, depending on the plant family. Olivares-Fuster et al. (2005) developed the electrochemical protoplast 
Fig. 1 Proposed general model of protoplast regeneration, representing parameter driven dedifferentiation, growth or differentiation inducers and inhibitors

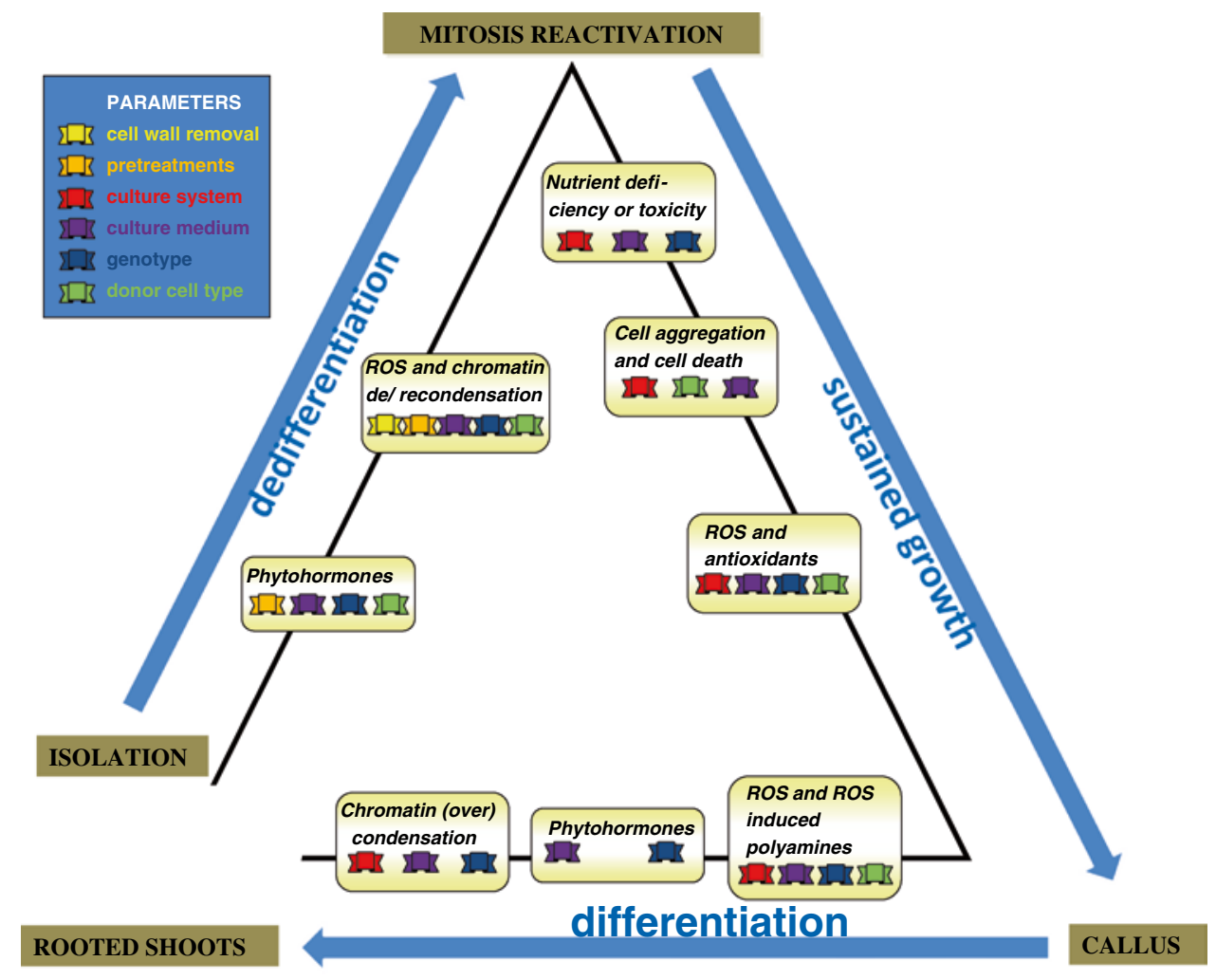

fusion method that combines the advantages of the two methods. It is based on chemically induced protoplast aggregation and direct current pulse promoted membrane fusion. According to the authors, high yields were obtained, but the system is not regularly implemented outside Rutaceae and requires the purchase of an electropulser.

Fusion events can be monitored with fluorescent markers, or by observing cell organelles. Pati et al. (2008) isolated heterokaryons by an innovative colony tracking technique in Rosa, based on differential fluorescent staining, and Borgato et al. (2007) monitored the efficiency of magnetic activated cell sorting. GFP transgenic lines have been used as tools for fusion monitoring (Table 2). The theoretical potential of flow cytometry for cell sorting is extended, but practical obstacles such as the preservation of a stable osmotic potential and the efficient recuperation of sorted protoplast populations are omnipresent and have so far inhibited flow cytometrical hybrid selection on a wide scale. Some novel technologies may offer an alternative sorting system for (fused) protoplasts or even cell nuclei. The Zeiss CombiSystem combines MicroTweezers for optical trapping and particle positioning with laser beam microdissection and subsequent laser directed transport in a collection vessel. Another potential innovative tool for cell sorting is DEPArray ${ }^{\mathrm{TM}}$ (Silicon Biosystems), a new platform based on moving dielectrophoresis cages. In the latter device, each suspended cell is trapped in a single cage and sorted after multiplexed fluorescent and morphological characterization. Cells can be selected individually, and friction is avoided. To our knowledge, these systems have not yet been used for selection of somatic fusion products.

Several techniques can be used for genome fragmentation, such as UV irradiation (Hall et al. 1992) or microprotoplasts (MPPs) (Yemets and Blume 2009). Genome fragmentation of the donor partner stimulates the elimination of much of its redundant genetic material in the somatic hybrid. Moreover, most karyotype instability causing donor genes are eliminated during the first post-fusion mitoses, as opposed to symmetrical fusions after which eliminations can occur up to the first sexually derived generation (Cui et al. 2009). In some cases, asymmetric fusions were realized without fragmentation treatment $(\mathrm{Li}$ et al. 2004). Asymmetric hybrids were obtained after protoplast fusion of UV treated Bupleurum scorzonerifolium and wheat. However, instead of B. scorzonerifolium chromosome fragments integrated in wheat, the reverse was found. This study can contribute to physical wheat genome maps (Zhou and Xia 2005). The same was observed when untreated Arabidopsis thaliana protoplasts were fused with UV treated Bupleurum protoplasts (Wang et al. 2005). It is suggested that the high amount of secondary metabolites is quenching ROS (Wang et al. 2011c).

A general problem is the quantification of DNA damage after an irradiation treatment. Abas et al. (2007) presented Comet assay single cell gel electrophoresis as a reliable tool to observe single and double strand breaks, and $\mathrm{Xu}$ 
Table 2 Innovative approaches for interspecific somatic hybrid selection or characterization in the period 2004-2013

\begin{tabular}{|c|c|}
\hline Tools & References $^{\mathrm{a}}$ \\
\hline Screening after fusion with GFP transformed fusion partner & Guo and Grosser (2005); Cai et al. (2006); Ovcharenko et al. (2011)* \\
\hline Heterofusion labeling of mitochondria & Sheahan et al. (2005) \\
\hline Genomic in situ hybridization & $\begin{array}{l}\text { Fu et al. (2004); Li et al. (2004); Xiang et al. (2004)*; Wang et al. } \\
\text { (2005)*, (2011a)*; Zhou and Xia (2005)*; Feng et al. (2006); Iovene } \\
\text { et al. (2007); Tu et al. (2008); Cui et al. (2009); Yang et al. (2009); Lian } \\
\text { et al. (2011); Patel et al. (2011); Jiang et al. (2012)* }\end{array}$ \\
\hline $\begin{array}{l}\text { InterRetroelement and retroelement microsatellite amplified } \\
\text { polymorphism }\end{array}$ & Patel et al. (2011) \\
\hline Microsatellite-anchored fragment length polymorphism & Thieme et al. (2010) \\
\hline 5.8S gene based species specific DNA marker & Prange et al. (2012) \\
\hline Chloroplast DNA cleaved amplified polymorphic sequence & $\begin{array}{l}\text { Fu et al. (2004); Takami et al. (2005); Trabelsi et al. (2005); Xu et al. } \\
\text { (2005), (2007)*; Cai et al. (2006); Bidani et al. (2007); Iovene et al. } \\
\text { (2007); Patel et al. (2011); Sarkar et al. (2011) }\end{array}$ \\
\hline Mitochondrial DNA cleaved amplified polymorphic sequence & $\begin{array}{l}\text { Fu et al. (2004); Takami et al. (2005); Xu et al. (2005); Cai et al. (2006); } \\
\text { Guo et al. (2007a); Iovene et al. (2007); Wang et al. (2010); Ovcharenko } \\
\text { et al. (2011)*; Patel et al. (2011); Sarkar et al. (2011) }\end{array}$ \\
\hline Real-time PCR & Ondrěj et al. (2010); Liu et al. (2012); Wang et al. (2013b) \\
\hline High resolution melting analysis & Deryckere et al. (2013) \\
\hline Microarray transcriptome analysis & Liu et al. (2012); Wang et al. (2013b) \\
\hline Reverse transcription PCR & Wang et al. (2011a*; Liu et al. (2012) \\
\hline Real-time reverse transcription PCR & Yu et al. (2012) \\
\hline
\end{tabular}

a Publications on asymmetric fusions are labeled with *

et al. (2007) revealed extensive DNA fragmentation with the terminal deoxynucleotidyl transferase biotin-dUTP nick end labeling assay.

We expect that alternative tissues, such as immature pollen, will be relatively more applied in the future for MPP production, because of the lack of synchronization requirement, as demonstrated for Lilium and Spathiphyllum (Saito and Nakano 2002; Lakshmanan et al. 2013). Moreover, MPPs could be selected based on filtration properties, which would result in different genome types, enabling researchers to attribute plant traits to particular chromosomes and further utilize MPPs accordingly. For subsequent characterization of MPPs, confocal laser scanning is a promising tool (Famelaer et al. 2007). Combining multiple techniques, such as irradiation of MPPs, or the creation of MPPs from unreduced gametes formed by interspecific hybrids offer a palet of innovative research in genome fragmentation and the transfer of recombined chromosomes.

\section{Characterization of somatic hybrids}

Chromosome constitution and stability

Both fertile and sterile hybrids are obtained after symmetric and asymmetric protoplast fusions. Frequent chromosomal abnormalities are a probable cause for male sterility in somatic hybrids (Iovene et al. 2012), and their occurrence has, therefore, been better studied of late. Various abnormal meiotic behaviors can occur in somatic hybrids: univalents, multivalents, lagging chromosomes, triads, polyads and chromosome bridges. The appearance of different numbers of univalents suggests the lack of homology of different chromosomes. The formation of multivalents may enable fusion partners to exchange genes and may suggest intergenome homology or another effect on hybrid fertility. Lagging chromosomes could contribute to the formation of small pollen grains that are linked to sterility (Guo et al. 2010). Apart from meiotic abnormalities, chromosome fragment deletion and rearrangements also occur in sterile somatic hybrids (Iovene et al. 2012).

For fertility, chromosome addition (meaning that the number of chromosomes in the hybrid equals the sum of the chromosomes in the fusion partners) is not absolutely required. Somatic hybrids that have the complete nuclear complements of both parents are generally rare (Xia 2009), and this fact has drawn more attention to the evaluation of chromosome number and structure stability following fusion. Fu et al. (2004) described an additive Citrus fusion in which chromosome translocations were observed. After various fusions, additive products were found alongside hybrids with reduced chromosome numbers (Wang et al. 2008b; Szczerbakowa et al. 2010; Lian et al. 2012), and in some cases the hybrid $2 \mathrm{C}$ level is lower than the $2 \mathrm{C}$ sum of both parent species (Sheng et al. 2008). Furthermore, regenerated fused genotypes are not always ploidy 
stable (Prange et al. 2010b; Sheng et al. 2011). Chromosome rejection as a consequence of the distant relationship between both partners is very likely (Guo et al. 2006). Whole chromosome block elimination and fragment loss upon genomic rearrangements are possible consequences (Guo et al. 2010). SSR markers are suitable tools to prove recombination through the occurrence of new bands and the disappearance of others (Guo et al. 2008). Regeneration ability is by itself the best possible tool to select hybrids with favorable genome complementation (Xiang et al. 2004).

The possible establishment of these complementations is evidently affected by the application of irradiation, which acts as a chromosome fragmenting or even eliminating agent on its own and thus interferes with the regeneration process (Jiang et al. 2012). Irradiation can speed up chromosome elimination, incompatibility alleviation, and differentiation. In the research of Wang et al. (2011b), irradiation driven ROS and flavonoid production were demonstrated; in our opinion, this can be of major importance toward the interference of ROS with regeneration in other crops. More profound research efforts could be directed toward the exact function of antioxidants during early divisions and genome stabilization. Possibly flavonoids are linked to the enigmatic preferential elimination of chromosomes of the non irradiated fusion partner after asymmetric hybridization described by Wang et al. (2005).

Chromosomal reduction due to transposon activity occurred in two somatic Oryza hybrids and suggested a potential to generate breeding lines with novel chromosomal constitutions. Shan et al. (2009) attributed the elevated transposon activity to the one-step introgression of multiple donor (Zizania latifolia) chromatin segments. Substantial loss of its original copies accompanied the activation of the element; this was not reported previously. This indicates that wide hybridization and subsequent introgression may activate transposable elements that are otherwise quiescent, and also suggests that, under certain conditions, along with mobilization of a transposon its original copy numbers can be dramatically reduced.

Genome stability and chromosome elimination require close monitoring. Causes for genome instability are extended: different cell cycle of genetically remote parents, smaller centromeres of eliminated chromosomes, DNA methylation of centromere function involved genes and cytoplasm containing secondary metabolites (Wang et al. 2008b). However, protoplast fusion based models may provide an excellent model to unravel the acquirement of karyotypic stability. For instance, somatic fusions have confirmed the probable harm of higher ploidy levels in this respect (Szczerbakowa et al. 2011). Cytogenetic techniques are indispensable for a thorough characterization of hybrid genome evolution upon fusion.
GISH has shown its potential for chromosome analysis, but requires well trained skills. The preparation of welldispersed chromosomes is the most important factor. Yet in Escalante et al. 1998, used it for somatic hybrid screening, and over the last years it developed into a standard screening tool (Table 2). We expect that the contribution of GISH to genome characterization studies after fusion will further increase, and researchers will exploit its complementarity with other techniques. For instance, a combination of FISH and GISH precisely identified Avena sativa chromosome segments introgressed in an asymmetric hybrid with Triticum aestivum (Xiang et al. 2010). When needed in other crops, the sensitivity of this combined technique could be increased by the application of tyramid FISH that can visualize chromosomal targets as small as $500 \mathrm{bp}$ on metaphase spreads (De Jong 2003). GISH acted complementary with SSR in demonstrating the genetic background of hybrids arisen after somatic fusion of 2 Triticum genotypes and Psathyrostachys (Li et al. 2004), and thus enabled the compilation of an asymmetric fusion protocol without the need for genome fragmentation in this particular combination. GISH could also be used for monitoring genomic stabilization. If chromosome elimination occurs preferentially rather than randomly, e.g., in Solanum (Trabelsi et al. 2005), it is a convenient tool to evaluate the effects of fusion and regeneration related parameters, and thus to optimize these parameters in an effort to stimulate or impede regeneration of particular genome types. A particular possible application of cytogenetic tools is the study of meiosis after somatic fusion to define chromosome affinity and phylogenetic relationship between the original fusion partners. On the other hand, the complementarity of two specific parents can be prescreened with GISH preceding fusion. As the probability toward successful hybridization increases along with parent complementarity, prescreening can be used to select partner combinations with relatively higher chances of success.

Genome, cytoplasmome, transcriptome and proteome screening

Molecular tools based on DNA analysis have known significant progress over the last years and are now routineously used for characterization of somatic hybrids. SSR, tandemly repeated in eukaryotic genomes, was used in SSR-PCR and in ISSR-PCR for somatic hybrid characterization. ISSR analysis showed that the level of intergenomic recombination can be increased by reducing ploidy level of Solanum hybrids, through androgenesis, by tetrasomic inheritance (Toppino et al. 2008). SSR markers are codominant and results are highly reproducible, whereas RAPD provides a useful screening tool when little is known about the DNA sequence of the test plants. Generally, the former 
marker is recommended over the latter, except in particular Solanum fusions (Sarkar et al. 2011). Alternative nuclear DNA markers are occasionally used for somatic hybrid screening (Table 2).

Recent tools such as microarray analysis or reverse transcription PCR have enabled hybrid transcriptome study (Table 2). Gancle et al. (2006) suggested proteomics as a good approach to better understand inheritance and regulation rules in somatic hybridization. In proteome analysis of Citrus somatic hybrids, among the differentially expressed spots proteins that can be linked are involved in photosynthesis, metabolism, and stress response, particularly to antioxidative stress. Cytosolic ascorbate peroxidase is upregulated, whereas it is downregulated in the chloroplasts; due to the peroxidase link with the ascorbate/glutathione cycle an effect on ROS scavenging may be expected. The antioxidative system is thus clearly affected by the hybrid status. Further proteome analysis indicates a better adaptation of the cybrid to cold or drought stress and an upregulated Rubisco activity (Wang et al. 2010). The complicated regulation mechanism between gene and protein can interfere with downstream hybrid monitoring; Liu et al. (2012) demonstrated introgression on the RNA level, but found little correlation between transcriptome and proteome.

The high demand for low-cost sequencing has stimulated high throughput (next generation) sequencing technologies development. These parallelize the sequencing process and thus simultaneously produce thousands or millions of sequences (Hall 2007). 500,000 Sequencing by synthesis operations may be run in parallel in ultra high throughput sequencing. Next generation sequencing enables fairly cheap high quality nucleic acid sequence data obtention of complete genomes in a short period of time, and will therefore definitely contribute to somatic hybrid genome screening and stability studies in the near future.

Somatic fusion can yield a combination of cytoplasms from different sources, unlike sexual cross hybridization that leads to maternal inheritance of cytoplasmic genomes (Xu et al. 2005). Before cytokinesis, unbiased chromosome partitioning is ensured by highly ordered nuclear inheritance. Likewise, the endoplasmatic reticulum, chloroplasts and mitochondria display distinctive partitioning strategies that guarantee unbiased inheritance before dedifferentiating cells have completed mitosis (Sheahan et al. 2004). For mitochondrial interaction after protoplast fusion at the subcellular level, Sheahan et al. (2005) fused protoplasts that contained either green fluorescent protein or MitoTrackerlabeled mitochondria. This allowed them to report the phenomenon of massive mitochondrial fusion that within $24 \mathrm{~h}$ led to a near-complete mixing of the mitochondrial population. It occurs in Medicago and Arabidopsis mesophyll protoplasts but not in protoplasts from already dedifferentiated cells like tobacco BY-2 or callus cultures. These results allow to more clearly interprete novel mitochondrial genotype development upon cell fusion. Sytnik et al. (2005) demonstrated that also chloroplasts can be transferred to remote species by protoplast fusion.

PCR-RFLP and CAPS analysis using mitochondrial or chloroplast universal primer pairs have been efficient and reliable tools for cytoplasmic genome characterization (Table 2). It is a relatively new somatic hybrid characterization tool (Cheng et al. 2003). Compared to RFLP with labeled probes, CAPS is more rapid, less expensive, and simpler (Guo et al. 2004). Chloroplast SSR is even more convenient and efficient, because enzyme cutting following PCR reaction is not required (Cheng et al. 2005). Also sequencing of common bands and searching for restriction endonuclease sites could be cheaper and more convenient than actual CAPS analysis, though after sequencing CAPS could be used to confirm the results.

Compared to nuclear DNA, inheritance of cpDNA and mtDNA is relatively complex. For Citrus fusion, the general consensus is that cpDNA is randomly transmitted; as for mtDNA, nearly all hybrids get theirs from the suspension parents (Fu et al. 2004; Guo et al. 2004; Takami et al. 2005). Guo et al. (2007a, b) described cpDNA coexistence in Citrus fusions. Whether this was persistent or just temporary due to incomplete elimination of cpDNA from 1 fusion partner, is still unclear. As the plant grew less vigorously and had fewer leaves, it is less competitive than the other fusion products, which may account for a selection toward non cpDNA coexistent types. In Solanum hybrids, coexistence of mtDNA was recorded (Sarkar et al. 2011).

Like nuclear genomes, cytoplasmic genomes are not always stable upon fusion. Intergenomic chloroplast recombination occurs rarely in higher plants, as opposed to the high level of mitochondrial recombination (Trabelsi et al. 2005). The latter occurs after various fusions (Xiang et al. 2004; Iovene et al. 2007; Yamagishi et al. 2008). In Triticum aestivum + Setaria italica hybrids, cpDNA coexistence as well as recombination occur (Xiang et al. 2004). It was also observed in Solanum tuberosum + verneï (Trabelsi et al. 2005), Solanum berthaultii + tuberosum (Bidani et al. 2007) and Bupleurum + Swertia (Jiang et al. 2012).

High resolution melting analysis, a screening technique based upon insertions, deletions or SNPs induced altered dissociation behavior of double stranded DNA, has become a highly sensitive method for genotyping (Wu et al. 2008). Deryckere et al. (2013) applied it to unravel mitochondria and chloroplast constitution in Cichorium somatic hybrids. High resolution melting can become a standard for mtDNA and cpDNA screening, as, through combination with a PCR reaction, it can outcompete laborious and costly sequencing analysis. Promising as it 
may be, it has its shortcomings in establishing recombination events and should for that aim be combined with sequencing.

\section{Agricultural valorization}

Genomic variation is of major interest in agricultural or industrial crops for plant quality and yield improvement. Salt tolerance, quality improvement, cytoplasmic male sterility (CMS) transfer, disease resistance, seedless triploids and rootstock improvement are the most common breeding goals for somatic hybridization in cash crops (Wang et al. 2013a). Most practical results were recently achieved in 'model families' Rutaceae, Brassicaceae and Solanaceae.

Somatic hybridizations and cybridizations in Citrus resulted in rootstocks resistant to biotic and abiotic constraints and in increased yield and fruit quality (Dambier et al. 2011), as well as in brown spot resistant scions (Soriano et al. 2012). New seedless triploid Citrus cultivars are produced via haploid + diploid fusion and symmetric fusions of elite diploid cultivars can lead to superior allotetraploid breeding parents (Grosser and Gmitter 2005). The endosperm balance number complicates sexual crosses in Solanum (Johnston et al. 1980). The most important objective in Solanum tuberosum somatic breeding is the introduction of resistance against the PVY virus, Colorado beetle and late blight (Phytophtora). Most hybrids are fertile and indeed contain some partial resistance against these parasites. Multiple resistances were also found, along with high morphological and agronomic variation (Thieme et al. 2010). Jiang et al. (2009) obtained Brassica napus + Camelina sativa hybrids with increased linolenic acid content compared to the B. napus partner. Scholze et al. (2010) produced the first resistant raphano-brassica symmetric and asymmetric hybrids. These showed new resistance types along with multiple resistances, including turnip mosaic virus. Other agriculturally relevant properties modified by somatic hybridization included chilling tolerance in Actinidia (Xiao et al. 2004), photoperiodical response in Gossypium (Sun et al. 2005b) and storage root formation in Ipomoea (Yang et al. 2009).

An important practical application of new genome/cytoplasmome combinations is the introduction of CMS (Cai et al. 2006). Fitter et al. (2005) demonstrated the possibility of introgressing CMS carried by mtDNA from a wild species into the cultivated crop. Yamagishi et al. (2008) proposed mitochondrial recombination as a tool for CMS introduction in cabbage. Lian et al. (2011) introduced CMS after Brassica juncea $+B$. oleracea fusion. Most hybrids were male sterile, although stamina appeared normal. Likewise, CMS and normal stamina simultaneously appeared after Arabidopsis + Bupleurum fusions (Wang et al. 2008b).

\section{Conclusions}

Somatic hybridization is one of many breeding tools available to create various new genomic combinations, and is essentially different from other techniques in many respects. When comparing somatic hybridization to transgenic approaches, the former enables to broaden the germplasm base, allows to transfer uncloned multiple genes and generates products that are not bound to the same legal regulations as transgene plants (Grosser and Gmitter 2005). Also, it transfers both mono- and polygenic traits (Thieme et al. 2004). Over the last years, it was frequently used as an alternative for incompatible sexual crossing, although apart from polyploidization other genomic effects, like chromosome rearrangements, are more typically observed in somatic hybrids than in their sexual counterparts (Chevre et al. 1994). Like sexual crosses, somatic fusions are confronted with their own particular troubleshooting and opportunities. Future studies will not only enlighten us on the particular differences in establishment of karyotypic stability through either method or their phenotypical consequences, but generate tools to overcome some of the drawbacks inherent to protoplast mediated hybridization, and increase the potential of the technique to create novelties with agriculturally improved traits. To this end, a further rationalization of protoplast regeneration is indispensable, and we expect that regeneration efforts will continue to steadily drop out of trial and error based experimentations. Especially, the further development of asymmetric hybrids can tackle problems that appear after somatic fusion, as it may limit genome conflicts. The fast evolution in marker development will allow more profound studies on genome stability. We will gain better insights on genetic backgrounds that are responsible for hybrid selection during the entire regeneration process.

\section{References}

Abas Y, Touil N, Kirsch-Volders M, Angenon G, Jacobs M, Famelaer I (2007) Evaluation of UV damage at DNA level in Nicotiana plumbaginifolia protoplasts using single cell gel electrophoresis. Plant Cell Tiss Org 91:145-154

Azad M, Yokota S, Ishiguri F, Yoshizawa N (2006) Plant regeneration from mesophyll protoplasts of a medicinal plant, Phellodendron amurense Rupr. In Vitro Cell Dev Plant 42:502-507

Bajaj Y (1989) Plant protoplasts and genetic engineering. Springer, Heidelberg

Bidani A, Nouri-Ellouz O, Lakhoua L, Sihachakr D, Cheniclet C, Mahjoub A, Drira N, Gargouri-Bouzid R (2007) Interspecific potato somatic hybrids between Solanum berthaultii and Solanum tuberosum $\mathrm{L}$. showed recombinant plastome and improved tolerance to salinity. Plant Cell Tiss Org 91:179-189

Borgato L, Conicella C, Pisani F, Furini A (2007) Production and characterization of arboreous and fertile Solanum melongena 
plus Solanum marginatum somatic hybrid plants. Planta 226:961-969

Briere C, Barthou H, Jauneau A, Alibert G, Petitprez M (2004) The actin cytoskeleton is involved in signalling protoplast embryogenesis induced by agarose embedding. Physiol Plantarum 122:115-122

Cai X, Liu X, Guo W (2006) GFP expression as an indicator of somatic hybrids between transgenic Satsuma mandarin and calamondin at embryoid stage. Plant Cell Tiss Org 87:245-253

Cassells A, Curry R (2001) Oxidative stress and physiological, epigenetic and genetic variability in plant tissue culture: implications for micropropagators and genetic engineers. Plant Cell Tiss Org 64:145-157

Castelblanque L, Garcia-Sogo B, Pineda B, Moreno V (2010) Efficient plant regeneration from protoplasts of Kalanchoe blossfeldiana via organogenesis. Plant Cell Tiss Org 100:107-112

Chabane D, Assani A, Bouguedoura N, Haicour R, Ducreux G (2007) Induction of callus formation from difficile date palm protoplasts by means of nurse culture. C R Biol 330:392-401

Chen L, Zhang M, Xiao Q, Wu J, Hirata Y (2004) Plant regeneration from hypocotyl protoplasts of red cabbage (Brassica oleracea) by using nurse cultures. Plant Cell Tiss Org 77:133-138

Cheng Y, Guo W, Deng X (2003) Molecular characterization of cytoplasmic and nuclear genomes in phenotypically abnormal Valencia orange (Citrus sinensis) + Meiwa kumquat (Fortunella crassifolia) intergeneric somatic hybrids. Plant Cell Rep 21:445-451

Cheng Y, De Carmen V, Meng H, Guo W, Tao N, Deng X (2005) A set of primers for analyzing chloroplast DNA diversity in Citrus and related genera. Tree Physiol 25:661-672

Chevre A, Eber F, Margale E, Kerlan M, Primard C, Vedel F, Delseny M, Pelletier G (1994) Comparison of somatic and sexual Brassica napus-Sinapis alba hybrids and their progeny by cytogenetic studies and molecular characterization. Genome 37:367-374

Conde P, Santos C (2006) An efficient protocol for Ulmus minor Mill. Protoplast isolation and culture in agarose droplets. Plant Cell Tiss Org 86:359-366

Cui H, Yu Z, Deng J, Gao X, Sun Y, Xia G (2009) Introgression of bread wheat chromatin into tall wheatgrass via somatic hybridization. Planta 229:323-330

Dai X, Xiao W, Huang X, Zhao J, Chen Y, Huang X (2010) Plant regeneration from embryogenic cell suspensions and protoplasts of dessert banana cv. 'Da Jiao' (Musa paradisiacal ABB Linn.) via somatic embryogenesis. In Vitro Cell Dev Plant 46:403-410

Dambier D, Benyahia H, Pensabene-Bellavia G, Kacar Y, Froelicher Y, Belfalah Z, Lhou B, Handaji N, Printz B, Morillon R, Yesiloglu T, Navarro L, Ollitrault P (2011) Somatic hybridization for Citrus rootstock breeding: an effective tool to solve some important issues of the Mediterranean Citrus industry. Plant Cell Rep 30:883-900

Davey M, Anthony P, Power J, Lowe K (2005) Plant protoplasts: status and biotechnological perspectives. Biotechnol Adv 23:131-171

Davey M, Anthony P, Patel D, Power J (2010) Plant Protoplasts: Isolation, Culture and Plant Regeneration. In: Davey M, Anthony P (eds) Plant cell culture: essential methods. John Wiley \& Sons, New York, pp 153-173

De Jong H (2003) Visualising DNA domains and sequences by microscopy: a fifty-year history of molecular cytogenetics. Genome 46:943-946

De Jong F, Mathesius U, Imin N, Rolfe B (2007) A proteome study of the proliferation of cultured Medicago truncatula protoplasts. Proteomics 7:722-736

Deryckere D, Eeckhaut T, Van Huylenbroeck J, Van Bockstaele E (2012) Low melting point agarose beads as a standard method for plantlet regeneration from protoplasts within the Cichorium genus. Plant Cell Rep 31:2261-2269

Deryckere D, De Keyser E, Eeckhaut T, Van Huylenbroeck J, Van Bockstaele E (2013) High-resolution melting analysis as a rapid and highly sensitive method for Cichorium plasmotype characterization. Plant Mol Biol Rep 31:731-740

Duquenne B, Eeckhaut T, Werbrouck S, Van Huylenbroeck J (2007) Effect of enzyme concentrations on protoplast isolation and protoplast culture of Spathiphyllum and Anthurium. Plant Cell Tiss Org 91:165-173

Eeckhaut T, Van Huylenbroeck J (2011) Development of an optimal culture system for callogenesis of Chrysanthemum indicum protoplasts. Acta Physiol Plant 33:1547-1551

Escalante A, Imanishi S, Hossain M, Ohmido N, Fukui K (1998) RFLP analysis and genomic in situ hybridization (GISH) in somatic hybrids and their progeny between Lycopersicon esculentum and Solanum lycopersicoides. Theor Appl Genet 96:719-726

Famelaer I, Verhoeven H, Dijkhuis P, Ramulu K (2007) A study of the process of synchronisation and micronucleation in Beta vulgaris and the monitoring of an isolation procedure for micronuclei and micro-protoplasts by confocal laser scanning microscopy and flow cytometry. Plant Cell Tiss Org Cult 90:169-179

Feng Y, Takahashi H, Akagi H, Mori K (2006) New interspecific rice genome constructions obtained by symmetric cell fusion. Plant Breed 125:403-404

Fitter J, Thomas M, Niu C, Rose R (2005) Investigation of Nicotiana tabacum $+N$. suaveolens cybrids with carpelloid stamens. J Plant Physiol 162:225-235

Fiuk A, Rybczynski J (2007) The effect of several factors on somatic embryogenesis and plant regeneration in protoplast cultures of Gentiana kurroo (Royle). Plant Cell Tiss Org 91:263-271

Fu C, Chen C, Guo W, Deng X (2004) GISH, AFLP and PCRRFLP analysis of an intergeneric somatic hybrid combining Goutou sour orange and Poncirus trifoliata. Plant Cell Rep 23: 391-396

Gancle A, Grimplet J, Sauvage F, Ollitrault P, Brillouet J (2006) Predominant expression of diploid mandarin leaf proteome in two citrus mandarin-derived somatic allotetraploid hybrids. J Agr Food Chem 54:6212-6218

Grosser J, Gmitter F (2005) Applications of somatic hybridization and cybridization in crop improvement, with Citrus as a model. In Vitro Cell Dev Plant 41:220-225

Grosser J, Calovic M, Louzada E (2010) Protoplast fusion technology-somatic hybridization and cybridization. In: Davey M, Anthony P (eds) Plant cell culture: essential methods. John Wiley \& Sons, New York, pp 175-198

Grzebelus E, Szklarczyk M, Baranski R (2012a) An improved protocol for plant regeneration from leaf and hypocotyl-derived protoplasts of carrot. Plant Cell Tiss Org 109:101-109

Grzebelus E, Szklarczyk M, Gren J, Sniegowska K, Jopek M, Kacinska I, Mrozek K (2012b) Phytosulfokine stimulates cell divisions in sugar beet (Beta vulgaris L.) mesophyll protoplast cultures. Plant Growth Regul 67:93-100

Guo W, Grosser J (2005) Somatic hylbrid vigor in Citrus: direct evidence from protoplast fusion of an embryogenic callus line with a transgenic mesophyll parent expressing the GFP gene. Plant Sci 168:1541-1545

Guo W, Prasad D, Cheng Y, Serrano P, Deng X, Grosser J (2004) Targeted cybridization in Citrus: transfer of Satsuma cytoplasm to seedy cultivars for potential seedlessness. Plant Cell Rep 22:752-758

Guo J, Liu Q, Zhai H, Wang Y (2006) Regeneration of plants from Ipomoea cairica $\mathrm{L}$. protoplasts and production of somatic hybrids between I. cairica L. and sweetpotato, I. batatas (L.) Lam. Plant Cell Tiss Org 87:321-327 
Guo W, Wu R, Cheng Y, Deng X (2007a) Production and molecular characterization of Citrus intergeneric somatic hybrids between red tangerine and citrange. Plant Breed 126:72-76

Guo Y, Bai J, Zhang Z (2007b) Plant regeneration from embryogenic suspension-derived protoplasts of ginger (Zingiber officinale Rosc.). Plant Cell Tiss Org 89:151-157

Guo W, Wu R, Cheng Y, Deng X (2008) Regeneration and molecular characterisation of two interspecific somatic hybrids of Citrus for potential rootstock improvement. J Hortic Sci Biotech $83: 407-410$

Guo X, Xie C, Cai X, Song B, He L, Liu J (2010) Meiotic behavior of pollen mother cells in relation to ploidy level of somatic hybrids between Solanum tuberosum and S. chacoense. Plant Cell Rep 29:1277-1285

Hall N (2007) Advanced sequencing technologies and their wider impact in microbiology. J Exp Biol 210:1518-1525

Hall R, Krens F, Rouwendal G (1992) DNA radiation-damage and asymmetric somatic hybridization-is UV a potential substitute or supplement to ionizing-radiation in fusion experiments. Physiol Plant 85:319-324

He G, Zhang J, Li K, Xiong Z, Chen M, Chang J, Wang Y, Yang G, Barnabas B (2006) An improved system to establish highly embryogenic haploid cell and protoplast cultures from pollen calluses of maize (Zea mays L.). Plant Cell Tiss Org 86:15-25

Holme I, Torp A, Hansen L, Andersen S (2004) Quantitative trait loci affecting plant regeneration from protoplasts of Brassica oleracea. Theor Appl Genet 108:1513-1520

Inoue K, Kato T, Kunitake H, Yabuya T (2004) Efficient production of polyploid plants via protoplast culture of Iris fulva. Cytologia 69:327-333

Iovene M, Savarese S, Cardi T, Frusciante L, Scotti N, Simon P, Carputo D (2007) Nuclear and cytoplasmic genome composition of Solanum bulbocastanum $+S$. tuberosum somatic hybrids. Genome 50:443-450

Iovene M, Aversano R, Savarese S, Caruso I, Di Matteo A, Cardi T, Frusciante L, Carputo D (2012) Interspecific somatic hybrids between Solanum bulbocastanum and $S$. tuberosum and their haploidization for potato breeding. Biol Plant 56:1-8

Ishii S (1987) Generation of active oxygen species during enzymic isolation of protoplasts from oat leaves. In Vitro Cell Dev Plant 23:653-658

Jiang J, Zhao X, Tian W, Li T, Wang Y (2009) Intertribal somatic hybrids between Brassica napus and Camelina sativa with high linolenic acid content. Plant Cell Tiss Org 99:91-95

Jiang L, Cai Y, Xia G, Xiang F (2012) Introgression of the heterologous nuclear DNAs and efficacious compositions from Swertia tetraptera Maxim. into Bupleurum scorzonerifolium Willd. via somatic hybridization. Protoplasma 249:737-745

Johnson A, Veilleux R (2001) Somatic hybridization and application in plant breeding. In: Janick J (ed) Plant Breeding Rev 20. John Wiley \& Sons, New York, pp 167-225

Johnston S, Den Nijs A, Peloquin S, Hannemann R (1980) The significance of genetic balance to endosperm development in interspecific crosses. Theor Appl Genet 57:5-9

Kakoniova D, Hlinkova E, Liskova D, Kollarova K (2010) Oligosaccharides induce changes in protein patterns of regenerating spruce protoplasts. Cent Eur J Biol 5:353-363

Kanwar K, Bhardwaj A, Deepika R (2009) Efficient regeneration of plantlets from callus and mesophyll derived protoplasts of Robinia pseudoacacia L. Plant Cell Tiss Org 96:95-103

Kielkowska A, Adamus A (2012) An alginate-layer technique for culture of Brassica oleracea L. protoplasts. In Vitro Cell Dev Plant 48:265-273

Kim J, Bergervoet J, Raemakers C, Jacobsen E, Visser R (2005) Isolation of protoplasts, and culture and regeneration into plants in Alstroemeria. In Vitro Cell Dev Plant 41:505-510
Klocke E, Weinzierl C, Abel S (2012) Protoplast fusion for the generation of unique Pelargonium plants. Acta Hort 953: s119-127

Ko J, Ju J, Lee S, Cha H (2006) Tobacco protoplast culture in a polydimethylsiloxane-based microfluidic channel. Protoplasma 227:237-240

Komai F, Morohashi H, Horita M (2006) Application of nurse culture for plant regeneration from protoplasts of Lilium japonicum Thunb. In Vitro Cell Dev Plant 42:252-255

Kwon H, Yokoyama R, Nishitani K (2005) A proteomic approach to apoplastic proteins involved in cell wall regeneration in protoplasts of Arabidopsis suspension-cultured cells. Plant Cell Physiol 46:843-857

Lakshmanan P, Eeckhaut T, Van Huylenbroeck J, Van Bockstaele E (2013) Micronucleation by mitosis inhibitors in developing microspores of Spathiphyllum wallisii Regel. Plant Cell Rep $32: 369-377$

Li C, Xia G, Xiang F, Zhou C, Cheng A (2004) Regeneration of asymmetric somatic hybrid plants from the fusion of two types of wheat with Russian wildrye. Plant Cell Rep 23:461-467

Lian Y, Lin G, Zhao X, Lim H (2011) Production and genetic characterization of somatic hybrids between leaf mustard (Brassica juncea) and broccoli (Brassica oleracea). In Vitro Cell Dev Plant 47:289-296

Lian Y, Zhao X, Lin G, Lim H (2012) Protoplast isolation and culture for somatic hybridisation of rapid cycling Brassica rapa with 'Anand' CMS and Brassica juncea. Plant Cell Tiss Org 109:565-572

Liu C, Li S, Wang M, Xia G (2012) A transcriptomic analysis reveals the nature of salinity tolerance of a wheat introgression line. Plant Mol Biol 78:159-169

Meyer L, Serek M, Winkelmann T (2009) Protoplast isolation and plant regeneration of different genotypes of Petunia and Calibrachoa. Plant Cell Tiss Org 99:27-34

Moricová P, Ondrěj V, Navrátilová B, Luhová L (2013) Changes of DNA methylation and hydroxymethylation in plant protoplast cultures. Acta Biochim Pol 60:33-36

Motte H, Galuszka P, Spíchal L, Tarkowski P, Plíhal O, Šmehilová M, Jaworek P, Vereecke D, Werbrouck S, Geelen D (2013) Phenyl-adenine, identified in a light-dependent short hypocotyls4-assisted chemical screen, is a potent compound for shoot regeneration through the inhibition of cytokinin oxidase/dehydrogenase activity. Plant Physiol 163:1229-1241

Niedz R (2006) Regeneration of somatic embryos from sweet orange (C. sinensis) protoplasts using semi-permeable membranes. Plant Cell Tiss Org 84:353-357

Olivares-Fuster O, Duran-Vila N, Navarro L (2005) Electrochemical protoplast fusion in Citrus. Plant Cell Rep 24:112-119

Ondrěj V, Navrátilová B, Lebeda A (2009) The heterochromatin as a marker for protoplast differentiation of Cucumis sativus. Plant Cell Tiss Org 96:229-234

Ondrěj V, Navrátilová B, Protivánková I, Piterková J, Sedlárová M, Luhová L, Lebeda A (2010) Recondensation level of repetitive sequences in the plant protoplast nucleus is limited by oxidative stress. J Exp Biol 61:2395-2401

Ovcharenko O, Momot V, Cherep N, Sheludko Y, Komarnitsky I, Rudas V, Kuchuk N (2011) Transfer of transformed Lesquerella fendleri (Gray) Wats. chloroplasts into Orychophragmus violaceus (L.) OE Schulz by protoplast fusion. Plant Cell Tiss Org 105:21-27

Pan Z, Liu C, Zobayed S, Saxena P (2004) Plant Regeneration from mesophyll protoplasts of Echinacea Purpurea. Plant Cell Tiss Org 77:251-255

Pan Z, Liu C, Murch S, Saxena P (2005) Optimized chemodiversity in protoplast-derived lines of St. John's wort (Hypericum perforatum L.). In Vitro Cell Dev Plant 41:226-231 
Papadakis A, Roubelakis-Angelakis K (1999) The generation of active oxygen species differs in Nicotiana and Vitis plant protoplasts. Plant Physiol 121:197-205

Papadakis A, Paschalidis K, Roubelakis-Angelakis K (2005) Biosynthesis profile and endogenous titers of polyamines differ in totipotent and recalcitrant plant protoplasts. Physiol Plantarum 125:10-20

Pasternak T, Potters G, Caubergs R, Jansen M (2005) Complementary interactions between oxidative stress and auxins control plant growth responses at plant, organ, and cellular level. J Exp Biol 56:1991-2001

Patel D, Power J, Anthony P, Badakshi F, Heslop-Harrison J, Davey M (2011) Somatic hybrid plants of Nicotiana $\times$ sanderae $+N$. debneyi with fungal resistance to Peronospora tabacina. Ann Bot 108:809-819

Pati P, Sharma M, Ahuja P (2005) Extra thin alginate film: an efficient technique for protoplast culture. Protoplasma 226:217-221

Pati P, Sharma M, Ahuja P (2008) Rose protoplast isolation and culture and heterokaryon selection by immobilization in extra thin alginate film. Protoplasma 233:165-171

Petrivalsky M, Vanickova P, Ryzi M, Návratilová B, Piterkova J, Sedlarova M, Luhova L (2012) The effects of reactive nitrogen and oxygen species on the regeneration and growth of cucumber cells from isolated protoplasts. Plant Cell Tiss Org 108:237-249

Potters G, Jansen M, Horemans N, Guisez Y, Pasternak T (2010) Dehydroascorbate and glutathione regulate the cellular development of Nicotiana tabacum L. SR-1 protoplasts. In Vitro Cell Dev Plant 46:289-297

Prange A, Bartsch M, Serek M, Winkelmann T (2010a) Regeneration of different Cyclamen species via somatic embryogenesis from callus, suspension cultures and protoplasts. Sci Hortic $125: 442-450$

Prange A, Serek M, Bartsch M, Winkelmann T (2010b) Efficient and stable regeneration from protoplasts of Cyclamen coum Miller via somatic embryogenesis. Plant Cell Tiss Org 101: 171-182

Prange A, Bartsch M, Meiners J, Serek M, Winkelmann T (2012) Interspecific somatic hybrids between Cyclamen persicum and C. coum, two sexually incompatible species. Plant Cell Rep 31:723-735

Rakosy-Tican E, Aurori A, Vesa S, Kovacs K (2007) In vitro morphogenesis of sunflower (Helianthus annuus) hypocotyl protoplasts: the effects of protoplast density, haemoglobin and spermidine. Plant Cell Tiss Org 90:55-62

Riazunnisa K, Padmavathi L, Scheibe R, Raghavendra A (2007) Preparation of Arabidopsis mesophyll protoplasts with high rates of photosynthesis. Physiol Plantarum 129:679-686

Saito H, Nakano M (2002) Isolation and characterization of gametic microprotoplasts from developing microspores of Lilium longiflorum for partial genome transfer in the Liliaceous ornamentals. Sex Plant Reprod 15:179-185

Sarkar D, Tiwari J, Sharma S, Sharma Poonam S, Gopal J, Singh B, Luthra S, Pandey S, Pattanayak D (2011) Production and characterization of somatic hybrids between Solanum tuberosum L. and S. pinnatisectum Dun. Plant Cell Tiss Org 107:427-440

Scholze P, Kramer R, Ryschka U, Klocke E, Schumann G (2010) Somatic hybrids of vegetable brassicas as source for new resistances to fungal and virus diseases. Euphytica 176:1-14

Shan X, Ou X, Liu Z, Dong Y, Lin X, Li X, Liu B (2009) Transpositional activation of mPing in an asymmetric nuclear somatic cell hybrid of rice and Zizania latifolia was accompanied by massive element loss. Theor Appl Genet 119:1325-1333

Sheahan M, Rose R, McCurdy D (2004) Organelle inheritance in plant cell division: the actin cytoskeleton is required for unbiased inheritance of chloroplasts, mitochondria and endoplasmic reticulum in dividing protoplasts. Plant J 37:379-390
Sheahan M, McCurdy D, Rose R (2005) Mitochondria as a connected population: ensuring continuity of the mitochondrial genome during plant cell dedifferentiation through massive mitochondrial fusion. Plant J 44:744-755

Sheahan M, Rose R, McCurdy D (2007) Actin-filament-dependent remodeling of the vacuole in cultured mesophyll protoplasts. Protoplasma 230:141-152

Sheng X, Liu F, Zhu Y, Zhao H, Zhang L, Chen B (2008) Production and analysis of intergeneric somatic hybrids between Brassica oleracea and Matthiola incana. Plant Cell Tiss Org 92:55-62

Sheng X, Zhao Z, Yu H, Wang J, Xiaohui Z, Gu H (2011) Protoplast isolation and plant regeneration of different doubled haploid lines of cauliflower (Brassica oleracea var. botrytis). Plant Cell Tiss Org 107:513-520

Shiba T, Mii M (2005) Plant regeneration from mesophyll-and cell suspension-derived protoplasts of Dianthus acicularis and characterization of regenerated plants. In Vitro Cell Dev Plant 41:794-800

Shrestha B, Tokuhara K, Mii M (2007) Plant regeneration from cell suspension-derived protoplasts of Phalaenopsis. Plant Cell Rep 26:719-725

Soriano L, Assis F, Camargo L, Cristofani-Yaly M, Rocha R, Andrade C, Alves F, Januzzi B (2012) Regeneration and characterization of somatic hybrids combining sweet orange and mandarin/mandarin hybrid cultivars for citrus scion improvement. Plant Cell Tiss Org 111:385-392

Sun Y, Zhang X, Huang C, Nie Y, Guo X (2005a) Factors influencing in vitro regeneration from protoplasts of wild cotton $(G$. klotzschianum A) and RAPD analysis of regenerated plantlets. Plant Growth Regul 46:79-86

Sun Y, Zhang X, Nie Y, Guo X (2005b) Production of fertile somatic hybrids of Gossypium hirsutum plus G. bickii and G. hirsutum plus G. stockii via protoplast fusion. Plant Cell Tiss Org 83:303-310

Sytnik E, Komarnytsky I, Gleba Y, Kuchuk N (2005) Transfer of transformed chloroplasts from Nicotiana tabacum to the Lycium barbarum plants. Cell Biol Int 29:71-75

Szczerbakowa A, Tarwacka J, Oskiera M, Jakuczun H, Wielgat B (2010) Somatic hybridization between the diploids of S. michoacanum and S. tuberosum. Acta Physiol Plant 32:867-873

Szczerbakowa A, Tarwacka J, Sliwinska E, Wielgat B (2011) Nuclear DNA content and chromosome number in somatic hybrid allopolyploids of Solanum. Plant Cell Tiss Org 106:373-380

Takami K, Matsumaru A, Yahata M, Kunitake H, Komatsu H (2005) Utilization of intergeneric somatic hybrids as an index discriminating taxa in the genus Citrus and its related species. Sex Plant Reprod 18:21-28

Thieme R, Darsow U, Rakosy-Tican L, Kang Z, Gavrilenko T, Antonova O, Heimbach U, Thieme T (2004) Use of somatic hybridization to transfer resistance to late blight and potato virus Y (PVY) into cultivated potato. Plant Breed Seed Sci 50:113-118

Thieme R, Rakosy-Tican E, Nachtigall M, Schubert J, Hammann T, Antonova O, Gavrilenko T, Heimbach U, Thieme T (2010) Characterization of the multiple resistance traits of somatic hybrids between Solanum cardiophyllum Lindl. and two commercial potato cultivars. Plant Cell Rep 29:1187-1201

Toppino L, Menella G, Rizza F, D’Alessandro A, Sihachakr D, Rotino G (2008) ISSR and isozyme characterization of androgenetic dihaploids reveals tetrasomic inheritance in tetraploid somatic hybrids between Solanum melongena and Solanum aethiopicum Group Gilo. J Hered 99:304-315

Trabelsi S, Gargouri-Bouzid R, Vedel F, Nato A, Lakhoua L, Drira N (2005) Somatic hybrids between potato Solanum tuberosum and wild species Solanum vernei exhibit a recombination in the plastome. Plant Cell Tiss Org 83:1-11 
Tu Y, Sun J, Liu Y, Ge X, Zhao Z, Yao X, Li Z (2008) Production and characterization of intertribal somatic hybrids of Raphanus sativus and Brassica rapa with dye and medicinal plant Isatis indigotica. Plant Cell Rep 27:873-883

Umate P, Rao K, Kiranmayee K, Jaya T, Sadanandam A (2005) Plant regeneration of mulberry (Morus indica) from mesophyllderived protoplasts. Plant Cell Tiss Org 82:289-293

Wang M, Xia G, Peng Z (2005) High UV-tolerance with introgression hybrid formation of Bupleurum scorzonerifolium Willd. Plant Sci 168:593-600

Wang J, Sun Y, Yan S, Daud M, Zhu S (2008a) High frequency plant regeneration from protoplasts in cotton via somatic embryogenesis. Biol Plantarum 52:616-620

Wang M, Zhao J, Peng Z, Guo W, Wang Y, Wang L, Xia G (2008b) Chromosomes are eliminated in the symmetric fusion between Arabidopsis thaliana L. and Bupleurum scorzonerifolium Willd. Plant Cell Tiss Org 92:121-130

Wang L, Pan Z, Guo W (2010) Proteomic analysis of leaves from a diploid cybrid produced by protoplast fusion between Satsuma mandarin and pummelo. Plant Cell Tiss Org 103:165-174

Wang J, Zhao C, Liu C, Xia G, Xiang F (2011a) Introgression of Swertia mussotii gene into Bupleurum scorzonerifolium via somatic hybridization. BioMedCentral Plant Biol 11:71

Wang M, Peng Z, Wang L, Zhao J, Che J, Xia G (2011b) Different rates of chromosome elimination in symmetric and asymmetric somatic hybridization between Festuca arundinacea and Bupleurum scorzonerifolium. Russ J Plant Physiol 58:133-141

Wang M, Peng Z, Wang M, Guo W, Zhao J, Zhi D, Xia G (2011c) The behavior of Bupleurum scorzonerifolium as a parent of somatic hybrid introgressed lines is associated with UV resistance of its chromosomes. Russ J Plant Physiol 58:615-621

Wang J, Jiang J, Wang Y (2013a) Protoplast fusion for crop improvement and breeding in China. Plant Cell Tiss Org 112:131-142

Wang X, Zhou J, Yang Y, Yu F, Chen J, Yu C, Wang F, Cheng Y, Yan C, Chen J (2013b) Transcriptome analysis of a progeny of somatic hybrids of cultivated rice (Oryza sativa L.) and wild rice (Oryza meyeriana L.) with high resistance to bacterial blight. J Phytopathol 161:324-334

Winkelmann T, Specht J, Serek M (2006) Efficient plant regeneration from protoplasts isolated from embryogenic suspension cultures of Cyclamen persicum Mill. Plant Cell Tiss Org 86:337-347

Wisniewska E, Majewska-Sawka A (2007) Arabinogalactan-proteins stimulate the organogenesis of guard cell protoplasts-derived callus in sugar beet. Plant Cell Rep 26:1457-1467

Wu S, Wirthensohn M, Hunt P, Gibson J, Sedgley M (2008) High resolution melting analysis of almond SNPs derived from ESTs. Theor Appl Genet 118:1-14

Wu F, Shen S, Lee L, Lee S, Chan M, Lin C (2009) Tape-Arabidopsis sandwich-a simpler Arabidopsis protoplast isolation method. Plant Meth 5:16

Xia G (2009) Progress of chromosome engineering mediated by asymmetric somatic hybridization. J Genet Genomics 36:547-556

Xiang F, Xia G, Zhi D, Wang J, Nie H, Chen M (2004) Regeneration of somatic hybrids in relation to the nuclear and cytoplasmic genomes of wheat and Setaria italic. Genome 47:680-688
Xiang F, Wang J, Xu C, Xia G (2010) The chromosome content and genotype of two wheat cell lines and of their somatic fusion product with oat. Planta 231:1201-1210

Xiao Z, Wan L, Han B (2004) An interspecific somatic hybrid between Actinidia chinensis and Actinidia kolomikta and its chilling tolerance. Plant Cell Tiss Org 79:299-306

Xiao W, Huang X, Huang X, Chen Y, Dai X, Zhao J (2007) Plant regeneration from protoplasts of Musa acuminata cv. Mas (AA) via somatic embryogenesis. Plant Cell Tiss Org 90:191-200

Xu X, Liu J, Deng X (2005) FCM, SSR and CAPS analysis of intergeneric somatic hybrid plants between Changshou kumquat and Dancy tangerine. Bot Bull Acad Sinica 46:93-98

Xu X, Hu Z, Li J, Liu J, Deng X (2007) Asymmetric somatic hybridization between UV-irradiated Citrus unshiu and C. sinensis: regeneration and characterization of hybrid shoots. Plant Cell Rep 26:1263-1273

Xu X, Xie G, He L, Zhang J, Xu X, Qian R, Liang G, Liu J (2013) Differences in oxidative stress, antioxidant systems, and microscopic analysis between regenerating callus-derived protoplasts and recalcitrant leaf mesophyll-derived protoplasts of Citrus reticulata Blanco. Plant Cell Tiss Org. 114:161-169

Yamagishi H, Nakagawa S, Kinoshita D, Ishibashi A, Yamashita Y (2008) Somatic hybrids between Arabidopsis thaliana and cabbage (Brassica oleracea $\mathrm{L}$.) with all chromosomes derived from A.thaliana and low levels of fertile seed. J Jpn Soc Hortic Sci 77:277-282

Yang X, Guo X, Zhang X, Nie Y, Jin S (2007) Plant regeneration from Gossypium davidsonii protoplasts via somatic embryogenesis. Biol Plantarum 51:533-537

Yang X, Tu L, Zhu L, Fu L, Min L, Zhang X (2008) Expression profile analysis of genes involved in cell wall regeneration during protoplast culture in cotton by suppression subtractive hybridization and macroarray. J Exp Bot 59:3661-3674

Yang Y, Guan S, Zhai H, He S, Liu Q (2009) Development and evaluation of a storage root-bearing sweet potato somatic hybrid between Ipomoea batatas (L.) Lam. and I. triloba L. Plant Cell Tiss Org 99:83-89

Yasuda K, Watanabe Y, Watanabe M (2007) Generation of intracellular reactive oxygen species during the isolation of Brassica napus leaf protoplasts. Plant Biotechnol 24:361-366

Yemets A, Blume Y (2009) Antimitotic drugs for microprotoplastmediated chromosome transfer. In: Blume Y, Baird W, Yemets A, Breviario D (eds) The plant cytoskeleton: a key tool for agrobiotechnology. Springer, Dordrecht, pp 419-434

Yu X, Chu B, Liu R, Sun J, Brian J, Wang H, Shuijin Z, Sun Y (2012) Characteristics of fertile somatic hybrids of G. hirsutum L. and G. trilobum generated via protoplast fusion. Theor Appl Genet 125:1503-1516

Zaban B, Maisch J, Nick P (2013) Dynamic actin controls polarity induction de novo in protoplasts. J Integr Plant Biol 55:142-159

Zhou A, Xia G (2005) Introgression of the Haynaldia villosa genome into gamma-ray-induced asymmetric somatic hybrids of wheat. Plant Cell Rep 24:289-296 